\title{
Gender/ing impact assessment: Can it be made to work?
}

\author{
Carol Bacchi \\ Politics Discipline, University of Adelaide, \\ South Australia, Australia
}

Forms of gender analysis are being introduced worldwide as new methods for achieving gender equality. This paper identifies limitations in dominant frameworks and puts forward suggestions to improve the process. It advances a form of deep evaluation to institutionalise conceptual analysis as a part of policy design. It also proposes the development of a Gendering Impact Assessment model that attends to the ways in which policy produces gender, and that has the potential to put in question the strategic norms of broad policy objectives.

Gender analysis is a tool associated with gender mainstreaming, the most recent innovation in equality policy. Broadly, mainstreaming is a commitment to guarantee that every part of an organisation assumes responsibility to ensure that policies impact evenly on women and men. Gender analysis, in its most common form, describes a methodology for assessing if policy is, or is not, attentive to the "differences" between women and men.

I specify "its most common form" because gender analysis has several incarnations. The approach has its genesis in the development field where there currently exists a plethora of frameworks (see March et al. 1999). Most of the major international organisations, including the United Nations, the World Bank and the ILO, employ forms of gender analysis. It is also being used in many Western democracies, including Canada, New Zealand, parts of Europe and the European Commission itself.

In Australia the Women's Budget Program (1984-1996) is often identified as a precursor of gender analysis models (Sharp and Broomhill 2002; Rankin and Vickers 2001). AusAID (1998) referred to gender analysis as a part of social analysis as early as 1998.' More recently, the Howard Government has signaled an interest in gender mainstreaming and gender analysis. The Office of the Status of Women has been shifted from the Prime Minister's Department to the 
Department of Family and Community Services, moving 'so-called women's issues into the mainstream' (Goward 2004). Federal Sex Discrimination Commissioner, Pru Goward (2004), announced that this move creates the opportunity for 'the entire public service to adopt gender analysis'. Given this development, it seems more important than ever to reflect upon just what 'gender analysis' entails.

For the sake of simplicity I identify two contrasting models. The first, associated with a rational policy development model (see Edwards 2001), appears in Canada, New Zealand and in international organisations. The second, a "gender relations" approach, is most comprehensively developed in The Netherlands. Below I outline the two approaches and indicate the reasons The Netherlands model offers more potential for change. I also suggest limitations in existing models, and directions that need to be explored to improve the process. Crucially, I argue that, in order to be effective, gender analysis processes need to provide scope for putting in question strategic policy goals and for attending to the ways in which policy produces gender.

\section{BACKGROUND: MAINSTREAMING AND GENDER ANALYSIS}

The move to mainstreaming has been driven, at least in part, by a frustration with the fact that efforts on behalf of women have tended to be located in separate institutional units, cut adrift from the seats of power. Hence, the directives of those units, it is argued, could easily be ignored. The insistence that all parts of an organization have a responsibility to attend to gender is an attempt, according to its supporters, to move away from this "ghettoisation".

While it is important to recognize "the role of the global feminist movement in the rapid take-up of gender mainstreaming" (True and Mintrom 2001), the reform is suspect in many quarters. In some cases those very units dedicated to pursuing women's interests have been disbanded on the grounds that they are no longer needed, since gender is now "mainstreamed". This same rationale has been used in some places to attack women-specific measures, including positive/affirmative action. When this is put together with the frequent under-resourcing of the mainstreaming agenda and its low profile in many organizations, it is unsurprising that some commentators conclude, with Eleanor Ramsay, that "[t]he compelling logic of the mainstreaming argument, that equity matters should become everyone's responsibility in the organization has distracted attention from the result, whether intended or not, that there is a danger that it will become nobody's" (Ramsay 1995 in Bacchi 2001a). ${ }^{2}$

Given this experience, feminists have attempted to find ways to ensure that gender mainstreaming improves upon, rather than weakens, efforts 
to institutionalize gender equality. To this end, the literature now tends to state explicitly that mainstreaming procedures need to accompany, not replace, dedicated women's units and women-specific measures, including positive/affirmative action:

Gender mainstreaming cannot fully develop, cannot thrive in a climate that does not allow the articulation of feminist organization, be it inside institutions or autonomous. Gender equality units are a valuable asset for gender mainstreaming. They do not become redundant. Their position should be strengthened, not weakened (Verloo 2002, 4).

For the same reason, to try to make gender mainstreaming work for women, it is described as a wide and complex process, including but not synonymous with gender analysis. For example, the Council of Europe (1998, 21-23) states explicitly that mainstreaming is "more than a genderbased approach". It lists the following as "necessary prerequisites or facilitating conditions for gender mainstreaming": political will, specific gender equality policy, statistics, comprehensive knowledge of gender relations, knowledge of the administration, necessary funds and human resources, and participation of women in political and public life and in decision-making processes (see also Mackay and Bilton 2000,1). The implication here is that, as a stand-alone initiative, the potential of gender analysis is clearly limited. I return to this point at the end of the paper.

Non-governmental organizations led the way in the 1980 s in implementing a shift in approach from a focus on "women" to attention to "gender" and mainstreaming. In policy terms this shift is commonly described as a move from Women in Development (WID) to Gender and Development (GAD) (Chant and Gutmann 2000). The goal of those committed to WID was to erase women's invisibility in development programs (White 1994, 99). The postulated reasons for the shift to GAD include the point raised above, to put an end to the "ghettoisation" of women's issues. In addition, the use of the term "gender" is invoked to challenge assumptions that women are destined by their biology to fill certain roles. Much of the literature draws a distinction between "sex" as biology and "gender" as socially constructed roles and characteristics. The turn to "gender" is also intended to be a means of drawing attention to the need for men to change. Practical examples to illustrate the importance of including an analysis of men's behaviors include the transmission of sexually communicated diseases, especially HIVIAIDS, and domestic violence. Finally, GAD highlights the gendered character of development bureaucracies and other related organizations, "in terms of their culture, rules and outcomes" (March et al. 1999, 9).

There is considerable disagreement in the development field about whether or not the turn to "gender" and mainstreaming has been useful. 
The closure of dedicated women's units and the removal of womenspecific reforms is one concern. In addition, in some places it seems that the introduction of the term "gender" has not changed much. As Ann Oakley $(1998,135)$ says, "A somewhat insidious synonymy between 'women' and 'gender' developed; men remained the sex, while women became the gender." Moreover, in places where men have been considered a necessary part of the equation, "gender" is used at times to divert attention to a new high-priority category, "men at risk" (Staudt 2003, 49).

The key distinction between gender analysis approaches, according to March et al. $(1999,9)$, is whether or not they remain "narrowly applicable to programmes and projects", or whether they are able "to broaden out and apply to the social organisational contexts". This is not a new problem. Feminists have consistentiy faced the difficulty of fitting proposals for change into existing institutional frameworks. According to March et al. (1999) only the DPU framework ${ }^{3}$ and Kabeer's (1994) Social Relations Approach provide the possibility for the kind of institutional analysis required to promote meaningful change. Below I compare the idealized rational framework developed in Canada and New Zealand, and The Netherlands "gender relations" approach, suggesting that the latter, which has distinct similarities with Kabeer's framework, offers a more sophisticated analysis of the relationship between gender and policy. However, even The Netherlands model has difficulty raising fundamental questions about social organizational contexts. The challenge here, I suggest, is to introduce a process able to put in question the assumed strategic norms of proposed or existing policies. Suggestions about ways to move in this direction are offered later in the paper.

\section{RATIONAL GENDER ANALYSIS VERSUS A GENDER RELATIONS APPROACH}

In Canada and New Zealand gender analysis flows from the idealized rational development model found in many standard policy texts. ${ }^{4}$ This conventional policy development framework conceives of policy as a sequence of stages: identifying the issue; defining desired/anticipated outcomes; information gathering; development and analysis of options; communication; evaluation (Women's Bureau 1997). The expressed goal is to ensure that the differential impact of policy on women and men is considered at each stage. To this end sex-disaggregated statistics, focused primarily on women and men's differential location in the labour market, are collected. There is an assumption that, since the goal of policy development is effective and efficient policy, policy makers will recognize the importance of addressing the "differences" in their target groups, women and men. The intention is to prevent "policy failure", as the New Zealand Ministry of Women's Affairs (MWA 2001) explains: "[g]ender analysis provides a basis for robust analysis of the differences between women's and 
men's lives, and this removes the possibility of analysis based on incorrect assumptions and stereotypes."

In contrast, the Dutch framework takes environmental impact assessment as a guide. The methodology is called EER, translated as Emancipation Impact Assessment, which highlights the connection. EERs follow the five steps of an Environmental Impact Assessment:

1) Description of current gender relations;

2) Description of probable developments without new policy;

3) Description and analysis of the new policy plan;

4) Description of potential effects on gender relations:

5) Evaluating the positive and negative effects on gender relations

(Verloo and Roggeband 1996).

A theoretical framework designed to answer three questions underpins the approach: Where are the structurally unequal power relations between women and men to be found? How do they function? And, how are they to be evaluated? The theoretical framework contains three elements: structures, processes and criteriä: "Structures" refers to the core of gender power relations, and which institutions and organizations are most important. Two structures are identified: the gendered division of labour, and the organisation of intimacy. "Processes" refers to the mechanisms that produce and reproduce the unequal power relations. Two are selected as pivotal: the distribution of resources, and the operation of rules (interpretations or norms) about or connected to gender. "Criteria" provide the normative ground for assessing whether a situation is to be positively or negatively judged. Three criteria are identified: equality, autonomy and pluriformity/diversity. Equality is interpreted to mean equality before the law, or equal treatment in similar circumstances. Autonomy is defined as the possibility for women to decide for themselves what is a good life. Taking autonomy into account ensures that equality means more than sameness or adaptation to a male norm. Pluriformity/diversity indicates a commitment to a society in which differences are not hierarchical (Verloo 2000). ${ }^{5}$

\section{Points of contrast}

- The Canadian/New Zealand rational development model focuses consistently on women and men as separate categories of people, indicated in the primary focus on gender-disaggregated statistics, whereas the starting place for analysis in The Netherlands is "gender relations". The latter focus, I maintain, is more useful because gender needs to be thought of as "a principle of social organization" (Ferree et al. 1999; see also Bacchi 2004) rather than as a characteristic of a person. 
- The Netherlands model usefully identifies unequal power relations between men and women as a necessary component of the analysis. In contrast, the Canadian approach endeavours to present itself as a neutral examination of "socioeconomic data broken down by gender" (Women's Bureau 1997, 22).

- The focus in The Netherlands on the gendered division of labour and on the organisation of intimacy promises a more comprehensive analysis than the rational development model which concentrates almost exclusively on the relationship between paid employment and family responsibilities. There is also more space in The Netherlands model to raise questions about the ways in which sexuality creates and reproduces "systemic differences in the positioning of different groups of people" (March et al. 1999, 103).

\section{LIMITS OF DOMINANT MODELS}

Dominant models of gender analysis tend to conceptualise the nature of the dynamic between policy and gender in limited ways. The rational development approach, for example, makes a case for policy to respond to "gender difference"'. As Fiona Wilson (1996 in Benschop and Dooreward 1998, 789) argues, "[i]nstead of looking at gender as a difference perhaps we need to look ... at how this is done." To see how gender is "done", we need to analyze the ways in which gender is "constructed as a relationship of inequality by the rules and practices of different institutions" (Kabeer 1994, 84). Four institutions are critical to this process: household/family, state, market, and community. Identifying the state as one institution involved in the production of unequal gender relations constitutes policy as a gendering process rather than a "response" to assumed static "differences" between women and men. Policy does not just "act upon" people; it is itself active in "creating" people (Bacchi 2005).

Doubtless, the Dutch model is more sensitive to this dynamic, but it still tends to focus on the "potential effects" of policy "on gender relations", as if these relations are fixed and/or stand outside the policy process. Despite the awareness among Dutch analysts of the ways in which "Ipjolicies and structures ... often institutionalize the maintenance and reproduction of the social construction of gender" (Council of Europe $1998,7)$, the gender impact assessment framework inadequately captures the role of policy in constituting subjects and subjectivities (Neddleton 1997, 208; Bacchi 1999, 45). As an example of this process, the lack of good, publicly funded child care will be one reason many women decide to work part-time or to forego paid labor. Along related lines, lack of pay equity encourages men to continue in full-time paid labor, instead of taking time to care for their children. 
The distinction drawn in many versions of gender analysis between practical gender needs and strategic gender needs is an attempt to capture the role of policy as a gendering process. The distinction is intended to make a deceptively simple point-that, if a policy attends only to the immediate practical needs of a woman, it will very likely reinforce the conditions that put her in that situation in the first place. Mark Lansky (2001, 499) states perceptively that addressing practical needs "makes gender roles easier to perform." Awareness of this limitation has led to the insistence that, alongside attempts to respond to practical needs, other reforms, which have more transformative potential, are required. These reforms, we are told, will attend to women's "strategic needs". Making a related point, Jahan (1995) draws a distinction between "integrationist" mainstreaming and "agenda-setting" mainstreaming. However, the focus on practical and strategic needs encourages a top-down analysis, where women are constituted as "needy" (Chant and Gutmann 2000, 51 fn 6; Beveridge et al. 2000). The distinction is also difficult to operationalise since every practical intervention has an effect on power relations, whether this is intended or not (Longwe 1995 in March et al. 1999, 20).

Maxine Molyneux's (1985) original distinction between practical and strategic interests is more promising theoretically. Molyneux introduced the concept of gender interests to distinguish "the interests that women, or men, have because of their gender from those which are due to their class, ethnicity, or other factors" (White 1994, 99). She had two goals: to deal with the increasing awareness that women are not a homogenous group, and to highlight the ways in which men's gender interests either accelerate or impede change. Both these issues - how to deal with "diversity" among women, and how to deal with men - are at the forefront of discussions about gender analysis.

Regarding the former, some models (see March et al. 1999) mention the importance of recognising the impact of class or ethnicity on women's experiences. Very few directly address the position of lesbians. In fact, the central focus in most gender analysis on the relationship between family responsibilities and paid labour almost assumes heterosexual family units as the target group. Katherine Teghtsoonian (1999) recommends that separate instruments be developed and elaborated for other groups, including Aboriginal women and lesbians, before there are attempts to blend the analyses.

Gender-Based Analysis (GBA) in Canada makes a token nod to address the differences among women. We are told that "[a]ll women and all men in Canadian society are not the same. Research shows that their life opportunities are affected by race, ability, geographic location, sexual orientation, and individual characteristics" (Women's Bureau 1997, 9). ${ }^{6}$ 
However, there is no explanation of how to integrate this insight into the analysis. By way of contrast New Zealand's program makes a genuine attempt to keep the distinctive position of Maori women in view (Teghtsoonian 2003a).

In so far as men are concerned, the focus in Canadian GBA on sexdisaggregated statistics tends to "a static and reductionist definition of gender (as woman/man)", failing to address the "relational aspects of gender, or power and ideology, and of how patterns of subordination are reproduced" (Baden and Goetz 1997, 3). By contrast, both The Netherlands model and Kabeer's Social Relations approach attend to men as "gendered beings". This means making "male gender-identities themselves an issue in development" (White 1994, 99). The argument here is that, for real change to take place in women's lives, men will also need to change. This focus is potentially transformative because it puts in question the male norms which characterise most of our institutions and organizations. Women are no longer the only ones under scrutiny, the only ones "done to", or the only ones who need to change.

On this point Molyneux's (1985) insistence that men have "gender interests" is a useful theoretical move, making it possible to reflect upon which of these interests work against change and which provide the basis for potential collaboration. Taking her lead from Molyneux, Sarah White (1994) uses Connell (1987) to address the ways in which gender forms the basis of hierarchies, not only between men and women, but also among men. Her examples are gay men, and young men in some contexts. It is also clear that, when men lose authority due to unemployment or deskilling, this will have effects on their relationships with women. Mark Lansky (2001, 94) makes this point: "lacking access to the breadwinner role, these men often define masculinity more in terms of sexual performance and displays of "toughness" (see also White 1994; Chant 2000). Here, the concept "masculinism" has more explanatory power than "masculinity" which, as an assumed descriptor of socialized traits, tends to sit outside the real advantages that accrue to some men in current social relations (Duerst-Lahti 2003; Eveline 1994). The turn to men therefore potentially provides a path to a demand for institutional change. It is inadequate, however, to describe men's and women's "actual lives" or "lived realities" as "similar" or "different"; rather we need to reflect upon the contexts that produce those experiences.

The chief obstacle blocking this breadth of analysis is the ex post or reactive character of gender analysis. That is, existing models offer ways to vet or "proof" existing or proposed policies. The analyses remain ex post despite attempts in Canada to insist that input is necessary early in the policy cycle, and despite the commitment in The Netherlands to cre- 
ate a "virtuous circle" whereby the results of EER are fed back into the policy-making system to create better (and ex ante) policy proposals (Mackay and Bilton 2000, 31). This is because the problem is more than a matter of timing. Ex post analysis tends to ask how a proposal or policy can be introduced with fewer negative effects for women, instead of examining how the policy or policy proposal is itself implicated in constituting the problem (Bacchi 1999b). That is, there is a lack of questioning of overall strategic norms. This leaves gender analysis subservient to other policy goals. Worse still, it adds a "veneer of legitimacy" to objectives that remain unexamined (Teghtsoonian 2003a).

I use the following examples to illustrate how the ex post character of gender analysis has meant an inability to put in question neoliberal premises in specific policy proposals, severely limiting the possibilities for progressive change:

- The World Bank's (2002, 5 fn 3) "Case for Mainstreaming Gender" has as a goal a "less rigid or extreme gender-based division of labour" in order to increase "female productive capital, which has important progrowth effects." The responsibilities of caring are difficult to address given this objective, as are the potential negative effects of a pro-growth ethic.

- New Zealand's Ministry of Women's Affairs (MWA 2001, 1) offers a gender analysis on retirement income which accepts as a "Defined Desired Outcome" the government's aim to "encourage greater financial selfreliance for retired people." With this as a goal, closed to interrogation, there is automatic acceptance of individual autonomy as a model for social relations, making it difficult to acknowledge the interdependence of people in many contexts.

- The European Commission's $(1998,17)$ Guide to Gender Impact Assessment takes as axiomatic the goal of "eliminating labour market rigidities". To this end the Guide endorses "positive action in favor of men to a careful selection of professions related to child care," ignoring the ways in which this policy entrenches groups of women in low-paying jobs or out of work altogether (Bacchi 1996, 113).

- In The Netherlands the New General Social Assistance Act (1996) places an emphasis on what is called the "activating effect". The obligation to work, or at least to apply for work, has been extended to lone mothers with children five years old or over. A GIA (Gender Impact Assessment) concluded that for most women the new Act means an improvement. As Plantenga $(2000,9)$ states, this ignores the absence of a "national framework for care" to accompany the "national framework of 
a general obligation to work. ${ }^{n}$

- Rosalind Petchesky $(1995,156)$ notes the "large silences" in the 1994 Programme of Action of the International Conference on Population and Development:

the practical implementation of this reproductive health and rights agenda will be impossible without the allocation of resources globally and nationally to assure the full funding of social programmes, especially health-in other words, without radically new development alternatives.

Petchesky's analysis makes explicit "the concrete links between macroeconomic policies and the materialisation of reproductive and sexual rights for all the world's women". Her point is that, unless macroeconomic frameworks are identified as crucial to people's lives, commitments to women's health needs will accomplish little. It follows that, to be effective, gender analysis needs to be able to put in question neoliberal economic frameworks (Teghtsoonian 2003b; Bacchi and Eveline 2004).

\section{NEW DIRECTIONS}

Both Kathleen Staudt (2003) and Mieke Verloo (2002) insist that the only way to ensure that gender analysis has the ability to move outside of and critique the broad premises of policy proposals, which ultimately limit the transformative potential of the analysis, is to put specific equality objectives onto the agenda. Staudt calls them "outcomes". In Verloo's (2002, 8) words, "the absence of precise objectives on reduced gender inequalities" means that the treatment of gender "can be easily located within, and then be subject to, other policy goals, such as employment creation, economic growth or poverty reduction." Both also emphasise the importance of community participation and consultation as a way of freeing analysts from the limitations imposed by their "inside government" positioning (see also Sharp and Broomhill 2002). Naila Kabeer (in March et al. $1999,14)$ agrees that community consultation and participation is one way to avoid the "project trap" - the tendency to see the goal in terms of effective implementation of a designated policy, leaving the broad goals of the policy outside scrutiny.

These are important directions to pursue. Another way forward, I suggest, is to formalize the need for conceptual analysis in policy design. To this end, I am developing a procedure I call "deep evaluation", which incorporates an ability to put in question the grounding premises of any proposed or existing policy. This framework is not a conventional form of evaluation, applied ex post to see if objectives have been achieved. Rather, as a form of ex ante policy analysis, it offers a way to scrutinize critically conceptual premises, modes of implementation, and conventional forms of 
evaluation.

Deep evaluation consists of a series of questions, with rationales provided for each, under two headings: Conceptual Premises and Operational Practices. Under Conceptual Premises I identify three foci for critical analysis in policy development: i) the meanings attached to key concepts; ii) how the problem is represented (Bacchi 1999b); iii) the ways in which context is represented. Under Operational Practices, I propose to examine five issues: i) location of responsibility for implementation ii) methods of analysis iii) resource allocation iv) forms of evaluation and v) training.

Deep evaluation is an intervention that can be deployed in any policy field, not just in the area of gender policy. Needless to say, therefore, it would need to be tailored to the goals of the analysts. These may be to examine a policy for its gendering effects, or to consider underlying premises about law enforcement, or to reveal premises about the goals of economic development. In each case the procedure is intended to open up political discussions about policy options, empowering policy activists (Yeatman 1998). It rests on the assumption that many involved in policy formulation want to do more than participate in a technocratic exercise, but need ways to insist that other forms of analysis are a legitimate part of their mandate. The hope is that deep evaluation will assist them in this task, in the specific case examined in this paper, facilitating the development of a new, more effective gender analysis processes.

Because the goal is to make gender analysis more democratic and less technocratic, any new framework, including deep evaluation itself, needs to be developed and refined in concert with policy staff in specific departmental contexts. It is crucially important to avoid the trap of developing a "one size fits all" approach, which has proven to be the downfall of many previous policy initiatives (Eveline 1994; Bacchi 1999a; Eveline 2001). The success of the project depends upon select staff with knowledge and expertise in the functions and culture of those government departments taking a high degree of ownership in the refining and testing of the process. ${ }^{7}$ For this reason Joan Eveline and 1 are currently engaged in a Linkage-funded project to test and evaluate Canadian and Dutch approaches to gender analysis in Western Australia and South Australia. The project is designed as an iterative process so that the experiences and views of policy workers can be fed back into proposals for modification of aspects of the gender analysis framework, used as the starting point for the process. The method I call deep evaluation will be tested for its potential to identify: i) the ways in which gender is a process, rather than a characteristic of a person; ii) the ways in which policy produces gender; iii) the masculine norms of seeing and doing which sustain a gen- 
dered "politics of advantage" (Eveline, 1994); iv) the broad contextual factors that impinge on transformative visions. Other issues to be addressed include: the extent to which community involvement is necessary; how to develop sound and realistic training programs; how to attend to the diversity among women. The long-term goal is to develop a uniquely Australian gender analysis method, which I call Gendering Impact Assessment, to be applied across the public sector in both states.

\section{CONCLUSION}

Turning to the question in the title - can gender analysis be made to work? - a first step towards development of an effective process, I suggest, is confronting and discussing the political implications of different gender analysis frameworks. One of the goals of this paper has been to initiate this process. It is important, I argue, to reflect upon the contrasting effects of a model which sees gender analysis as a matter of "evening up" "differences" between women and men, and a method which confronts issues to do with power and gender relations.

A second goal has been to insist upon the need to empower those committed to gender analysis to put in question the strategic goals of the policies they are asked to "vet" for their differential impacts. Establishing deep evaluation as a necessary step in policy formulation is recommended as a means to achieve this goal. The focus in deep evaluation on representations of "problems" and representations of contexts, for example, encourages scrutiny of important international developments in trade and commerce, raising questions about the dangers of accepting these developments as given. This kind of conceptual interrogation, I suggest, provides the starting place for development of an innovative and reflexive gender analysis process, with the potential to broaden the gender equality agenda in important ways. Specifically, it creates the opportunity to draw attention to the role of policy in producing gender, and to make it clear that gender equality requires attending to general policy objectives.

Needless to say, there is no suggestion here that any stand-alone method of gender analysis can achieve real and meaningful change. Clearly, the introduction of a Gendering Impact Assessment process should form part of a wider agenda that includes women-specific reforms and affirmative action to increase women's representation in positions of influence (Bacchi 1996). Indeed, these reforms must be pursued alongside campaigns for the introduction of deep evaluation and Gendering Impact Assessment in order to increase the likelihood that these initiatives will be accepted and applied. Finally, to those who suggest that turning to the state is unwise in a period when states are being 'hollowed out', I insist, with Rankin and Vickers $(2001,21)$, that engagement remains critical since states are being internationalized, not eliminated. 


\section{NOTES}

1. Some more interesting developments are taking place in several States. In addition, the Women's Electoral Lobby demanded a "gender impact analysis of proposed budgetary measures" in their 2003 pre-budget submission (WEL 2003). A group of policy makers and academics also produced a gender analysis of the questions posed for the recent Constitutional Convention in South Australia (Donaghey 2003). AusAID (1998) referred to gender analysis as a part of social analysis as early as 1998 .

2. The concept is viewed with suspicion by women's organizations in Australia "where it has been seen to have provided the rationale for abolishing or downgrading women's units, services and policies at various government levels, by different administrations, at different times" (Mackay and Bilton 2000, 62; see also Bacchi 2000, 2001a, 2001b). Referring to the development arena, where mainstreaming originated, Caren Levy et al. $(2000,94)$ note that “GAD [Gender in Development] can jeopardize decades of work when it is used as a rationale for dispensing with the organizational structures created for WID Women in Development], without proper thought to its replacement." On the European front, Alison Woodward $(2001,4)$ identifies a similar concern that "states actually use the policy as an excuse to reduce woman-focused programming."

3. The DPU (Development Planning Unit), University College, London, usefully breaks down WID and GAD into subcategories that reflect the climate of prevalent political and economic thought in particular periods. So, for example, we get "the WID equity approach", followed by "the WID anti-poverty approach (1970s)", followed by "the WID efficiency approach (1980s/90s) under structural adjustment and economic efficiency measures", and "the GAD efficiency approach", "the GAD equity approach" and "the GAD anti-poverty approach". The DPU employs these subcategories to highlight the crucial impact of macro-economic climates on equality policy.

4. In this paper I concentrate on the model of gender analysis employed at the federal level in Canada. It is important to note that, because of decentralizing of decision-making, there are important differences in design and implementation in some Canadian provinces. British Columbia, for example, actually anticipated the development of a federal model by introducing The Gender Lens in 1993. While this framework had challenging components to it, since a neoliberal government has come to power, it has been replaced with a much less comprehensive framework. See British Columbia 2003; Teghtsoonian 2003b.

5. It is important to note that Dutch theorists continue to explore and develop the conceptual framework of an EER. In 1998, Mieke Verloo, the person responsible for The Netherlands approach, suggested adding one more structure, the organization of citizenship, one more mechanism, violence, and one more criterium, care/social responsibility. To date these suggestions have not been taken up. Verloo 2001, 18 fn 14.

6. This mention of "individual characteristics" suggests links with the equity approach, diversity management, which preceded gender-based analysis in Canada and which tends to individualize the problem of inequality. See Bacchi 1999a. On 
this point Woodward (2001, 2 fn 2) notes the ease with which mainstreaming, with its focus on "building equality into the culture of the organization and treating the employee as a whole person with respect and dignity", can become part of human resource management rather than a specific policy approach.

7. An example here is the model developed in a current Linkage project with the WA Police Service (Eveline and Harwood 2002). That model, called "companionate leadership" (Booth and Eveline 2001), is proving successful in building a team who "own" the organizational responsibility for designing and implementing their collaboratively chosen projects.

\section{REFERENCES}

AusAID. 1998. A Guide to Gender and Development.

$<$ http://www.ausaid.gov.au>

Bacchi, C. 1996. The Politics of Affirmative Action: 'Women', Equality and Category Politics. London: Sage.

1999a. Managing Diversity: A Contested Concept. International Review of Women and Leadership, 5(2), 1-9.

1999b. Women, Policy and Politics: The Construction of Policy

Problems. London: Sage.

2000. The Seesaw Effect: Down Goes Affirmative Action, Up Comes Workplace Diversity. Journal of Interdisciplinary Gender Studies, 5(2), 64-83. Special Issue: Gender and Workplace Relations.

2001a. Managing Equity: Mainstreaming and 'Diversity' in Australian universities. In A. Brooks and A. Mackinnon (Eds.) Gender and the Restructured University: Changing Management and Culture in Higher Education. Buckingham: Open University Press.

2001b. Gender Mainstreaming: A New Vision, More of the Same, or Backlash? Dialogue: Academy of the Social Sciences, 20, 1620.

2005. Policy. In P. Essed, A. Kobayashi and D. T. Goldberg (Eds.) Blackwell Companion to Gender Studies. London: Blackwell.

Bacchi, C. and Eveline, J. 2004. Mainstreaming and Neoliberalism: A Contested Relationshp. Policy \&Society: Journal of Public, Foreign \& Global Policy, 22(2), 98-118.

Baden, S. and Goetz, A.M. 1997. Who Needs [Sex] When You Can Have [Gender]?: Conflicting Discourses on Gender at Beijing. Feminist Review, 56, 3-25. 
Benschop, Y. and Dooreward, H. 1998. Covered by Equality: the Gender Subtext of Organizations. Organization Studies, 19(5), 787-805.

Beveridge, F., Nott, S. and Stephen, K. 2000. Moving Forward with Mainstreaming. In F. Beveridge, S. Nott and K. Stephen (Eds.) Making Women Count: Integrating Women into Law and Policy-making. Aldershot: Ashgate.

British Columbia. 1993. Gender Lens: A Guide to Gender-inclusive Policy and Program Development. Vancouver: Ministry of Women's Equality.

British Columbia. 2003. Guide to Best Practices in Gender Analysis. Vancouver: Ministry of Community, Aboriginal and Women's Services.

Chant, S. 2000. From 'Woman-Blind' to 'Man-Kind': Should Men Have More Space in Gender and Development? IDS Bulletin ,31(2), 7-17.

Chant, S. and Gutmann, M. 2000. Mainstreaming Men into Gender and Development: Debates, Reflections, and Experiences. GB: Oxfam.

Connell, R. 1987. Gender and Power. Oxford: Polity Press.

Council of Europe. 1998. Conceptual Framework, Methodology and Presentation of Good Practices: Final Report of Activities of the Group of Specialists on Mainstreaming [EG-S-MS (98) 2]. Strasbourg. $<$ http:/lwww.dhdirhr.coe.fr/equality/Eng/Final\%20Report20Mainstreaming. html>

Donaghey, T. 2003. Women and the South Australian Convention: Submission to the Constitutional Convention. Adelaide: University of South Australia.

Duerst-Lahti, G. 2003. Masculinism as Governing Ideology: Epistemological Consequences. Available at

http://www beloit. edu/ polisci/GDL/georgiamasculinism. htm]

Edwards, M. 2001. Social Policy, Public Policy: From Problem To Practice. Crows Nest, NSW: Allen \& Unwin.

Eisenstein, H. 1996. Inside Agitators: Australian Femocrats and the State. Philadelphia: Temple University Press.

European Commission. 1998. A Guide to Gender Impact Assessment. Employment \& Social Affairs. Equality between women and men. Luxembourg: Office for Official Publications of the European Commission. 
Eveline, J. 1994. The Politics of Advantage. Australian Feminist Studies, Special Issue: Women and Citizenship, 19 (Autumn), 129-54.

2001. Feminism, Racism and Citizenship in Twentieth Century Australia. In P.Crawford and P. Maddern (Eds.) Women as Australian Citizens: Underlying Histories. Melbourne: Melbourne University Press.

Eveline, J. and Booth, M. 2001. Gender and Sexuality in Discourses of Managerial Control. Gender, Work and Organizations, 9(5), 556-578.

Eveline, J. and Harwood, S. 2002. Policing the Margins of Collaborative Leadership: Gender and Culture Change in the WA Police Service. 11 th International Women in Leadership Conference, Churchlands Campus, ECU, November.

Ferree, M., Lorber, J. and Hess, B.B. Eds. 1998. Revisioning gender. London: Sage.

Goward, Pru (2004) 'Now Everyone Can Focus On Women', The Melbourne Age, 30 October.

Haas, L. 1992. Equal Parenthood and Social Policy. A Study of Parenting in Sweden. New York: State University of New York Press.

Jahan, R. 1995. The Elusive Agenda: Mainstreaming Women in Development. London: Zed Books.

Kabeer, N. 1994. Gender-aware Policy and Planning: A Socialrelations Perspective. In Mary Macdonald (Ed.) Gender Planning in Development Agencies: Meeting the Challenge (pp.80-97). UK: Oxfam.

Lansky, M. 2001. Gender, Women and all the Rest (Part II). International Labour Review, 140(1), 85-115.

Levy, C., Taher, N. and Vouhe, C. 2000. Addressing Men and Masculinities in GAD. IDS Bulletin, 31(2), 86-96.

Longwe, S. 1995. Supporting Women's Development in the Third World: Distinguishing between Intervention and Interference. Gender and Development, 3(1): 47-50.

Mackay, F. and Bilton, K. 2000. Learning From Experience: Lessons in Mainstreaming Equal Opportunities. University of Edinburgh: Governance of Scotland Forum.

March, C., Smyth, I., and Mukhopadhyay, M. 1999. A Guide to Gender-Analysis Frameworks. GB: Oxfam. 
Molyneux, M. 1985. Mobilization Without Emancipation? Women's Interests, the State, and Revolution in Nicaragua. Feminist Studies, 11(2), 227-254.

MWA (Ministry of Women's Affairs) New Zealand. 2001. GenderBased Policy Analysis: A Resource for Policy Analysts. Auckland: MWA.

Neddleton, S. 1997. Governing the Risky Self: How to become Healthy, Wealthy and Wise. In A. Petersen and R. Bunton (Eds.) Foucault, Health and Medicine (pp.173-222). New York: Routledge.

Oakley, A. 1998. Science, Gender, and Women's Liberation: An Argument against Postmodernism. Women's Studies International Forum, 21(2), 133-146.

Petchesky, R. P. 1995. From Population Control to Reproductive Rights: Feminist Fault Lines. Reproductive Health Matters, 6, 152-161.

Plantenga, J. 2000. Gender Impact Assessment and the Employment Strategy: The Case of the Netherlands. External Report commissioned and presented to the European Commission. $<w w w 2$.umist.ec.uk/management/ewerc/publications/2000-2001.html> (Accessed 16 November 2002).

Ramsay, E. 1995. The National Framework for Institutional Equity in Australian Higher Education - Current Achievements and Future Possibilities. Paper presented to the Second National Conference on Equity and Access in Tertiary Education, Melbourne, 3-7 July.

Rankin, L. P. and Vickers, J. 2001. Women's Movements and State Feminism: Integrating Diversity into Public Policy. Ottawa: Status of Women Canada. <http://www.swc-ctc.gc.ca/research/0106060662657756-e.html> Accessed on 26 November, 2002.

Sawer, M. 2003. The Life and Times of Women's Policy Machinery in Australia. In S. M. Rai (Ed.) Mainstreaming Gender, Democratizing the State? Institutional Mechanisms for the Advancement of Women (pp.243264). Manchester: Manchester University Press.

Sharp, R. and Broomhill, R. 2002. Budgeting for Equality: The Australian Experience, Feminist Economics 8(1): 25-47.

Staudt, K. 2003. 'Gender Mainstreaming: Conceptual Links to Institutional machineries' in Shirin M. Rai (ed.) Mainstreaming gender, democratizing the state: Institutional mechanisms for the advancement of women (pp.40-66). Manchester: Manchester University Press. 
Teghtsoonian, K. 1999. Centering Women's Diverse Interests in Health Policy and Practice: A Comparative Discussion of Gender Analysis. Paper prepared for Made to Measure: Accessing Approaches to Eliminate Gender Inequity, hosted by the Maritime Centre of Excellence for Women's Health, Halifax, Nova Scotia. $<$ http://www.medicine.dal.ca/acewh/eng/reports/teghtsoonian.pdf>

2000. Gendering Policy Analysis in the Government of British Columbia: Strategies, Possibilities, and Constraints. Studies in Political Economy, 61, 105-127.

2003a. Gender Analysis Mainstreaming in Aotearoa/New Zealand. Paper presented at the ECPR Joint Sessions, Edinburgh.

2003b. W(h)ither Women's Equality? Neoliberalism, Institutional Change and Public Policy in British Columbia, Policy Organisation \& Society, 22, 1, 26-47. Special Issue: 'The Politics of Women's Interests'. Guest Editors: Louise Chappell and Lisa Hill.

True, J. and Mintrom, M. 2001. Transnational Networks and Policy Diffusion: The Case of Gender Mainstreaming. International Studies Quarterly, 45: 27-57.

Verloo, M. 2000. Making Women Count in The Netherlands. In F. Beveridge, S. Nott and K. Stephen (Eds.) Making Women Count: Integrating gender into law and policy-making (pp.49-76). Dartmouth: Ashgate.

2001. Another Velvet Revolution? Gender Mainstreaming and The Politics of Implementation. IWM Working Paper No. 5. Vienna: IWM.

2002. The Development of Gender Mainstreaming as a Political Concept for Europe. Conference on Gender Learning, Leipzig, 6-8 September.

Verloo, M. and Roggeband, C. 1996. Gender Impact Assessment: The Development of a New Instrument in the Netherlands. Impact Assessment, 14(1), 3-21.

WEL (Women's Electoral Lobby). 2003-2004 Pre-budget submission. Canberra: WEL.

Wilson, F. 1996. Research Note: Organizational Theory: Blind and Deaf to Gender? Organization Studies, 17(5), 825-842.

White, S. 1994. Making Men an Issue: Gender Planning for 'the Other Half. In M. Macdonald (Ed.) Gender Planning in Development Agencies: Meeting the Challenge (pp.98-109). GB: Oxfam. 
Woodward, A. 2001. Gender Mainstreaming in European Policy: Innovation or Deception? Discussion Paper FS 101-103. Wissenschafftszentrum Berlin Fur Sozialforschung.

Women's Bureau, Strategic Policy Branch. 1997. Gender-based Analysis Backgrounder. Ottawa: Women's Bureau.

World Bank. 2002. Integrating Gender into the World Bank's Work: A Strategy for Action. http://www. worldbank. org/gender

Yeatman, A. Ed. 1998. Activism and the Policy Process. Sydney: Allen \& Unwin. 